\title{
Determinants for the success of software startups: Insights from a regional cluster
}

\author{
Paulo Afonso and João M. Fernandes \\ ORCiD: 0000-0003-3882-2491 and 0000-0003-1174-1966 \\ Email: psafonso@dps.uminho.pt and jmf@di.uminho.pt \\ Dept. Produção e Sistemas and Dept. Informática / Centro ALGORITMI \\ Universidade do Minho, Braga, Portugal
}

\begin{abstract}
Summary. In recent years, we have seen a growing interest in technologybased companies and intensive knowledge. Several regional clusters have appeared supported in dynamic entrepreneurial ecosystems which, alongside intrinsic aspects of the business, are important determinants of the success of new companies. However, most startups created in these innovation-oriented spaces do not survive the first years of life, due to the high competitiveness of the technological market, due to deficiencies in the business model, due to the support conditions provided by the surrounding ecosystem, and finally due to a weak adjustment between all these dimensions. Among several models available, the Early-Life Decision Model (ELDM) presents itself as an interesting framework for studying the development and success conditions of software companies. This article discusses the application of the ELDM based on a series of interviews conducted to 15 Portuguese software startups installed in a technological cluster located in the northeast of Portugal. Based on the results obtained, it was appropriate to add a new dimension to the ELDM model (learning) and complementing it with the perspectives of the business type and internal versus external determinants.
\end{abstract}

Key words: software development; startups; Early-Life Decision Model; business model; technology clusters.

\section{Introduction}

There have been proliferating ecosystems to support technological-based startups and intensive knowledge. However, due to the high competitiveness of the technology market and the current global economic crisis, most of these startups do not survive in their first years of life. Indeed, the failure rate of these companies in their first years of life is relatively high. Most software startups (between $50 \%$ to $80 \%$ ) fail during the first five years of their existence [1, 2].

According to Ries [3], these companies are created to build a new product or service under conditions of extreme uncertainty and are based on business models that are in a dynamic development process, being constantly changing to adjust to the market. This author adds that a startup needs to be in a constant 
learning process that ensures the sustainability of it. This is assured by the buildmeasure-learn feedback loop of creating and testing solutions and products, used to measure and learn from customers reactions in order to improve the product and achieve a good fit with the market.

The importance of testing and prototyping is also highlighted by Osterwalder and Pigneur [4], who argue that exploring multiple directions allows to learn more and discover better value propositions. Furthermore, Ries argues that innovation is at the heart of the success of these companies and that this innovation can be achieved in a number of ways, notably, reuse of existing technology on the market, planning a business model that unlocks or creates hidden value and direct the value proposition to customers not yet served by existing solutions.

It is therefore essential to understand the differences between startups that fail and those that have success in the market and what are the reasons for such differences. Sutton indicates that these companies face challenges, such as the fact that they have little or no operational history, have limitations in the resources at their disposal, face multiple influences often contradictory, and are highly affected by the dynamism of technologies and markets [5]. In many cases, a major reason for the failure of startups is the lack of skills of their entrepreneurs.

Entrepreneurial ecosystems play an important role in this process of leveraging technological startups. There is a growing technological, entrepreneurial and innovation cluster in the Northwest of Portugal, particularly in the axis Braga-Porto-Aveiro. Given these circumstances, there is an increase demand for software products and services, which greatly encourages the emergence of new startups. Therefore, several entrepreneurs have been motivated to open their own businesses, and increasingly new software startups have been created. According to some studies ${ }^{1}$, in Portugal, startups represent $6.5 \%$ of the companies and $18 \%$ of the new jobs. In this context, several business cooperation initiatives have been launched, with particular importance for the information and communication technologies sector (ICT). For example, in 2014, the Braga Municipality, in partnership with the local agency for the investment promotion, established a strategic plan for the economic development of the Braga cluster, in order to make it more attractive to investors and entrepreneurs. The Braga cluster began between the years 2000 and 2003 with the launching of several initiatives of business cooperation (called "business circles"). Based on the potential of the region, notably the presence of the University of Minho and the consequent supply of qualified human resources, the IT sector has naturally gained a particular importance.

The study reported in this manuscript aims to understand how startups enter the market and what distinguishes those that survive in the market from the remaining ones, through the evaluation of internal and external determinants of success. Thus, this manuscript contributes for understanding the conditions in which entrepreneurs build their startups, increasing the chances of success in the development of software products and services with market viability. Particularly, this manuscript explores the Early-life Decision Model (ELDM), a model

\footnotetext{
${ }^{1}$ Jornal de Negócios (Portuguese business newspaper), 08.nov.2013. URL
} 
composed of several decision types that can be taken by entrepreneurs to ensure business sustainability.

ELDM is a model for supporting the development of startups [6]. It consists of four dimensions presented in the form of a four-leaf clover, in which each leave represents a dimension. These dimensions become crucial for the newly created companies to sustain themselves in the market and to obtain profits that support and leverage the business.

The research methodology adopted was the semi-structured interview, since it presents the most appropriate characteristics for the purpose of this study. CEOs, CTOs, and founders of startups were interviewed, because they have a complete and solid knowledge of the history of the company. Accordingly, a series of interviews in 15 companies were prepared and conducted. The data obtained with these interviews was complemented with additional general information related to the companies (e.g., number of employees, year of foundation, sales volume) providing a rich set of information for analysis.

The organization of this manuscript is the following. Firstly, an introduction about the ELDM (sect. 2) is presented. The research approach taken during the study, which is based on semi-structured interviews, is explained in sect. 3. In sect. 4, the internal and external determinants found throughout this study are used to analyze the type of decisions made by software startups, particularly, the determinants related to the "shaping the company" dimension suggested in the ELDM. This section also presents the results in a four-quadrant matrix that allows a more complete analysis among different types of companies, internal determinants vs. external ones, and the respective impact. Sect. 5 discusses the main findings of this study, taking into account the four major dimensions of the ELDM. Finally, sect. 6 discusses the major conclusions of the manuscript and points out some possible ideas for future work.

\section{Early-Life Decision Model}

Startups in general and software startups in particular are pushed to take several decisions in their early-life. These decisions and related results can be important determinants for the success of these companies. The different decision types have been discussed through several models and categorizations namely, the business model canvas (BMC), proposed in [4], the managerial growth conceptualization for small software firms by Miettinen et al. [7] or the top five management priorities in the product-software market identified by Hoch et al. [8].

These models are related to several management focus areas such as marketing, partnering, globalization, people management and development. van Cann et al. [6] share this general approach and their four decision categories presented in the Early-Life Decision Model (ELDM) correspond to the main focus areas found by Hoch et al. and also discussed by other authors. Thus, the ELDM can be a good framework of analysis in this context.

The Early-Life Decision Model (ELDM) highlights the relevant decisions that entrepreneurs can address in their startups. These decisions are grouped into 
four dimensions: (1) shaping the company, (2) developing the product ${ }^{2},(3)$ es- $^{-}$ tablishing the market, and (4) going international. The ELDM can be applied by entrepreneurs who want to achieve success in their startups, and should take into consideration all types of decision that are distributed by the four dimensions.

To obtain these dimensions, van Cann et al. conducted structured interviews with the founders of 16 dutch software companies [6]. Through these interviews, the authors analyzed the various decisions that were made by the founders, with both positive and negative impact. The dimensions of the ELDM are represented in the form of a four-leaf clover, because some of the participants in the study considered that luck was a key factor in the success of their companies. This four-leaf clover is represented in Fig. 1.

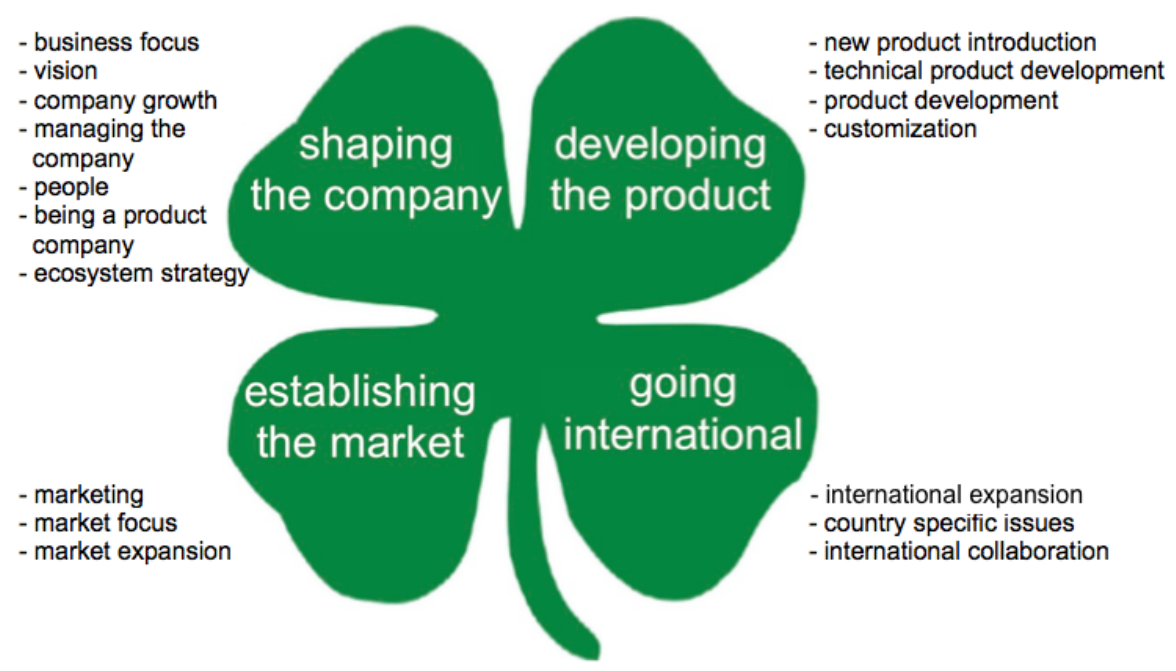

Fig. 1. Early-life Decision Model (ELDM) for software entrepreneurs [6].

In total, the clover covers 17 types of decision indicated by the participants of the study, where each one belongs to a study dimension. The "shaping the company" dimension is the most important to be analyzed, because it is considered as the starting point of startups. The "developing the product" dimension represents decisions that can be made in the course of both early and later phases of the startups life cycle, when for example the product is extended or innovation is tried. The "establishing the market" dimension is also very important for the business, and finally the "going international" dimension, which does not apply to many startups, since it requires more employees, resources and experience in the market. The impact of decisions related to these dimensions is significant in the progress of the companies.

\footnotetext{
${ }^{2}$ The original designation is 'product development'.
} 
Although this manuscript explores the four ELDM dimensions, more attention is given to the "shaping the company" dimension, since it is the first step of many startups to achieve success. Additionally, it is the most consistent dimension in the decisions presented by the participants in [6]. Therefore, in this first dimension, the decisions concerning the beginning of the life cycle of a start-up are considered. These decisions include (1) the definition of the business focus, (2) the establishment of a vision, (3) the design of the company's growth strategy, (4) the issues related to the management of the company, the people, and the human capital, (5) the decision about selling products, services, or both, and (6) opportunities and constraints related to the ecosystem. Additionally, this is the dimension that contains the largest number of decision types.

It is important to mention here how the principles of the Business Model Canvas suggested by Osterwalder and Pigneur and the logic of the Lean Startup approach proposed by Eric Ries can be related to the ELDM.

Osterwalder and Pigneur [4] propose a template for business modeling, composed of nine building blocks: (1) the value proposition, (2) customer relationships, (3) channels, (4) customer segments, (5) key activities, (6) key resources, (7) key partners, (8) revenue streams, and (9) cost structure.

Furthermore, Eric Ries founded the Lean Startup movement with the aim of supporting the creation and management of startups, notably in fostering a new vision on the way in which these companies develop and launch their products in the market [3]. The Lean Startup approach gives particular attention to the initial phase of a startup. It is mainly concerned with three aspects: (1) the way in which a value proposition is built, based on the market fit principle between the product and the customer/market; (2) the concept of a minimum viable product (MVP); and (3) the need for a continuous adjustment or pivoting of the business model. The goal of any startup is to build, in the shortest possible time, the products and services that customers are willing to pay, suggesting an iterative and recursive approach based on the cycle "Build-Measure-Learn".

\section{Research method}

In qualitative research, the researcher seeks to understand the whole phenomenon in question and to capture the context of global research. He has few preconceived ideas and he dedicates a considerable part of the research effort to interpret the events that occurred [9]. The collection of data is done without using formal and structured instruments, and the researcher emphasizes subjectivity to understand and interpret the data, analyzing in a systematic and inductive way the information obtained, which is usually narrated in the first person through semi-structured interviews. Thus, semi-structured interviewing was the method selected for the collection of the data in the different companies involved in this study.

Planning the interview In the process of planning and organizing the interviews, the following aspects were taken into consideration: 
- definition of the inclusion criteria to select the companies to be involved in this research study;

- preparation of the documents necessary for conducting the interviews;

- definition of a list of companies that could be included in the study;

- identification of candidate interviewees from the list of companies;

- submission of invitations to participate in the study.

Selecting the companies Some of the inclusion criteria previously identified were defined on the basis of the ones defined in the design of the ELDM [6] and in the study on innovation and entrepreneurship reported in [10]:

- being a Portuguese company active in the market;

- having headquarters in the region;

- being in the market for about 5 years (i.e., between 3 and 7 );

- having at least three employees;

- having obtained profits during its existence;

- being a software company that offer value to customers;

- being interested in participating/collaborating in the study.

Our initial set of companies was comprised of 21 companies, from which 15 were effectively included in the study.

Interview Guide Subsequently, the documents needed to carry out the interviews were elaborated. Two scripts of the interview were created and a confidentiality document was sent to each participant. The script that guided the interview is composed of the following parts:

1. General information: this part consists of topics needed to generate control variables, related to information about the respondent and the company;

2. Business design and market entry strategy: it is composed of issues and topics related to the definition of the market, the market entry strategy, and the internal and external constraints to the initial strategy;

3. Business growth strategy: concerning key moments in business growth and development, the evolution of the value proposition and changes in the relationship with the market and the business model;

4. Economic and financial aspects: it contains issues and topics on the cost structure and sources of revenues, investment, financing and profitability, and business management practices;

5. Final aspects: to give to the respondent the opportunity to give his/her opinion or suggestions and to give space for questions that may emerge from the interview.

Pilot interview A pilot interview was prepared to test the interview guide, in order to correct and improve some aspects. Other objectives in performing this interview were (1) to prepare how to conduct the interview, (2) to gain experience in the collection of data, (3) to realize if the average time previously established for each part of the interview was correctly estimated, and obviously (4) to collect the first set of informations. 
Interviewees For each selected company, a co-founder was identified who held a leadership position in the company, because he/she is usually a person who knows well the business. In this process, several persons who held positions of leadership in the selected companies were identified (preferably CEOs and CTOs), to proceed to invite them to participate in the research study.

Data analysis After the interviewing process, the collected data was analyzed and processed. For data identification and categorization, a software application (NVivo) for qualitative data analysis was used. An analysis of the cases was carried out individually and a cross-examination was also conducted. Additional information about the companies was collected and an individual follow-up report was sent to each one for validation purposes.

Companies The 15 software companies that agreed to cooperate in our study were categorized in three different groups, based on their value propositions (i.e., the type of systems they develop). Software companies develop software systems which refer to the result of executing a project [11]. In this study, each category includes five companies classified as:

1. Own projects (OP): development of a portfolio of own projects, i.e., the company takes the initiative to develop its own software products, web platforms, and/or mobile applications;

2. Bespoke projects/services (BP): development of applications/systems tailored to customers;

3. Own projects and Bespoke projects/services (OP\&BP): this group includes companies that simultaneously address the two previous profiles.

The most relevant determinants for each decision type that characterize each dimension of the ELDM were identified and discussed in the three groups of companies.

\section{Analysis of Findings}

The internal and external determinants found throughout this study were taken into account to analyze the type of decisions made by software startups. These determinants are focused on the "shaping the company" dimension suggested in the ELDM. Additionally, we present the results in a four-quadrant matrix that allows a comparison/analysis among different types of companies, internal determinants vs. external ones, and the respective impact.

\subsection{Internal and external determinants}

The analysis of the information from the 15 companies allow us to conclude that the decisions were composed of several fundamental determinants, which can be divided into two groups: internal determinants and external determinants. 
These determinants were identified and analyzed. Here, the ones that characterize the category "shaping the company", are presented and discussed.

Business focus: The internal determinants are related to internal decisions of the company, that is, decisions taken by the co-founders at the beginning of the business, such as the beginning of the activity and the foundation of the company, the business models adopted and the chosen value proposition. On the other hand, external determinants are related to external business factors, such as the fact that the company was born in an academic context, the business areas, and the markets explored.

Vision: The internal determinants are based on decisions taken by business leaders, which directly influenced their internal functioning. The external determinants are related to decisions that influenced the relationship between the companies and the market approached.

Company growth: Internal determinants are based on decisions taken by the business leaders, who have influenced the internal growth of the companies, such as the robustness of the value proposition, the first acquisitions, and the initial investment. The external determinants are related to the received (financial) support, such as obtaining external investment from several entities.

Managing the company: The internal determinants are related to the resources of the companies, namely human resources and technological equipment. External determinants are related to the access to supplies, external inputs and general facilities.

People: The internal determinants are based on decisions taken by business leaders at the beginning of the activity, such as the number of co-founders, their expertise, and the first contractors and subcontracts. The external determinants are related to factors prior to the beginning of the business activity and therefore not controllable by the co-founders. These include the institutions of higher education where the responsible person got his/her degree, their academic areas, the professional experience of the co-founders, their age when founding the companies, as well as experience in leadership roles and/or participation in academic groups.

Ecosystem strategy: These determinants are related to external factors of the companies. After an analysis of the strategic ecosystem of the companies, a set of three external determinants were defined: (1) the entry into the market, (2) the established partnerships, and (3) the external support of various entities.

\subsection{ELDM Matrix}

Once the analysis of the data collected in each type of decision of the four dimensions comprising the ELDM, a matrix divided into four quadrants was created as illustrated in Fig. 2. It considers a horizontal axis (relative to the three groups of companies) and a vertical one (relative to the type of determinants). As one moves from left to right along the horizontal axis, the group of companies gradually varies from the ones with own projects to those that offer services (with the origin of the axes representing both aspects). On the vertical axis, as one moves from the bottom to the top, the type of determinants begins to be 
exclusively external and becomes totally internal (with the origin representing an equal contribution of internal and external determinants).

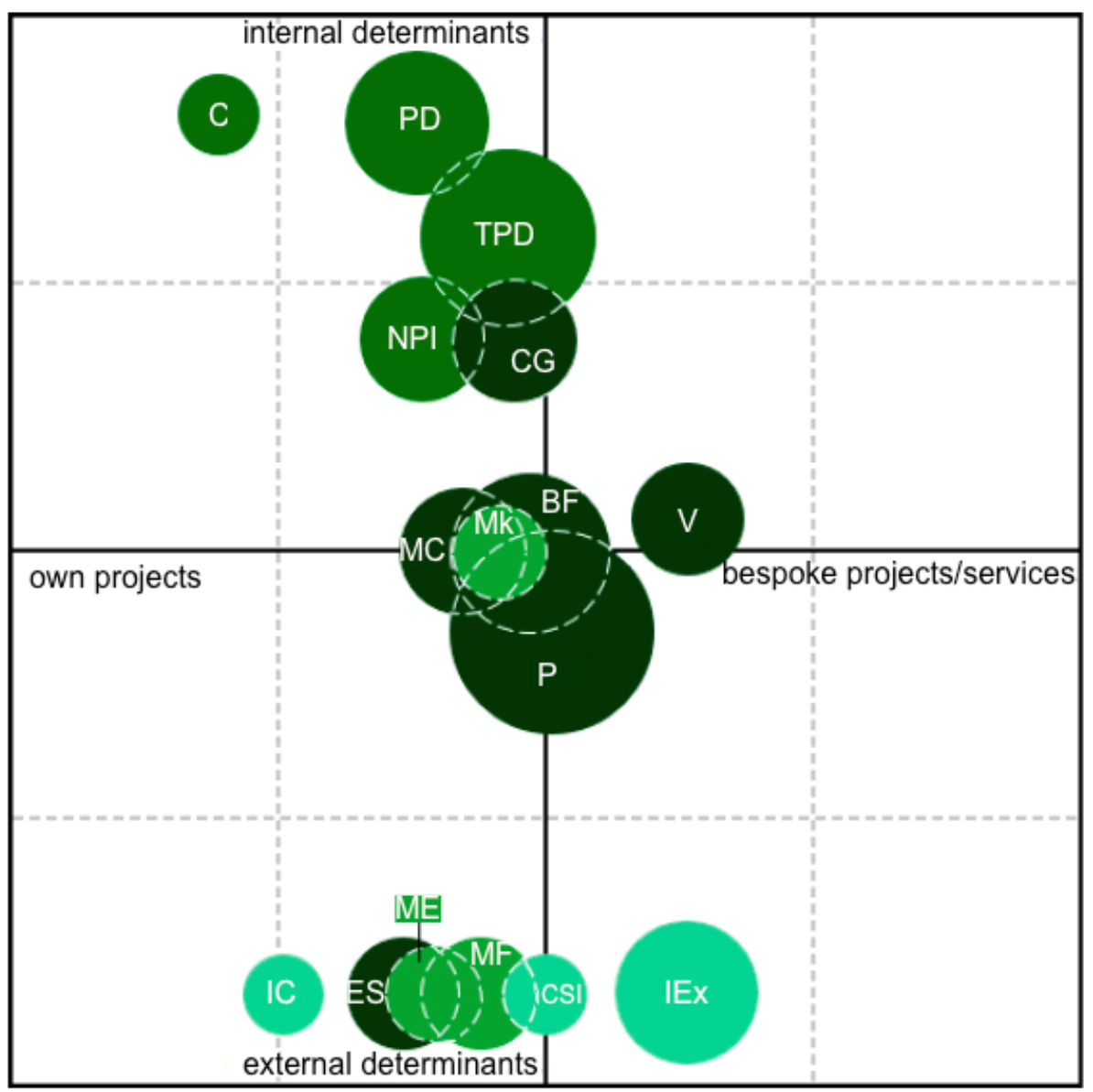

Fig. 2. ELDM matrix and determinants by company category. Dimensions "shaping the company" (BF - business focus, V - vision, CG - company growth, MC - managing the company, P - people, ES - ecosystem strategy); "developing the product" (NPI new product introduction, TPD - technical product development, PD - product development, C - customization); "establishing the market" (Mk - marketing, MF - market focus, ME - market expansion); "going international" (IEx - international expansion, CSI - country specific issues, IC - international collaboration)

Due to the large number of identified determinants (a total of 60), it was decided to refer to the 16 types of decision actions presented in the ELDM. Indeed, as stated by Cann et al., categorizing the decisions gives a basis for the analysis of the high number and variety of early-life decisions [6]. In order to position each type of decision on the matrix, its tendency in terms of the three 
groups of companies identified was considered. As an example, one can verify in the matrix that the type of decisions related to 'People' influences companies with both own products and services (even if slightly displaced to the services), and that the type of decisions related to 'Customization' has a greater influence on companies with own projects. The same applies to the vertical axis of the matrix. For example, one can verify that the aspects related to the 'Technical Product Development' presents more internal determinants than external ones, and that 'International Collaboration' is more related to external than internal determinants.

Once the position of each type of decision has been defined in the matrix, the radius of its representative circle was calculated. For this calculation, the number of determinants identified in the 16 types of decisions was taken into account. In this way, the radius dimension depends on the quantity of the identified determinants. As an example, one can notice that 'International Expansion' presents more (in this case, five) determinants than the specific issues of the country (in this case, just one).

Then, four different colors were assigned to the dimension which they belong to. Despite the different shades presented, the color chosen for all determinants was the green, because it is a allusive color to the luck factor, which is important to the success of companies. The tonality was gradually attributed to each dimension according to the number of identified determinants and the influence they had in the case studies. In this way, the tonality with the greatest dark hue was assigned to the dimension that presents the highest number of determinants, and which had the greatest impact on the study cases. On the other hand, the lightest hue is related to the dimension with the smallest number of identified determinants, and which had the less significant impact on the case studies.

\section{Discussion}

In this section, we discuss the main findings of the study presented in this manuscript, according to the four main dimensions of the ELDM and distinguishing internal from external factors. We also propose an extension of the ELDM, with a new learning dimension. Finally, some validity threats are discussed.

\subsection{Shaping the company}

After a first analysis of the elaborated matrix, one verifies that "shaping the company" is the most present dimension in the two business configurations (own projects and service provision) and the most balanced in terms of the number of internal and external determinants (14 internal and 15 external), compared with the remaining three ELDM dimensions. In fact, Ries [3] gives special importance to this dimension as a key source for companies to achieve success.

Among the six types of decision that make up this dimension, the 'People' one presents the biggest number of identified determinant (four internal and five 
external). It is also the largest of the 16 types and it occupies a central place in the matrix. In both cases, and as in the analysis carried out in the 15 cases that were studied, special attention was given to the innovation factor (present in the 'Vision' decision), considered a central aspect to the success of the companies and achieved through creativity and differentiation.

\subsection{Developing the product}

It is possible to verify that "Developing the product" is the dimension with the second largest number of determinants (14 internal and three external). We can conclude that this dimension is especially dependent on decisions taken and internal factors occurring within the company, thus becoming a more controllable dimension for entrepreneurs. Although they were presented in both axes, the identified determinants had a greater influence on the companies with own projects.

Some of the factors mentioned in the study on software development in startups [12] were proven in the analysis of the 15 study cases. Other factors to take into account and which have been found in almost all of the 15 cases of study are related to the execution of a thorough pre-market study and the existence of good software project management.

\subsection{Establishing the market}

The "establishing the market" dimension is present in the two considered axes and has less determinants identified than the first two dimensions. Almost all of the identified determinants are external to the business (one internal and six external) and therefore it depends on market factors.

\subsection{Going international}

Internationalization is the only dimension that does not occur in all companies of this study, since some of them chose to exclusively address the national market to start the business and to expand the value proposition. This also occurs in the study carried out in [6], which mentions that we do not find this dimension in many startups. International collaboration is the determinant that further deviates from the balance of the two axes, having a greater influence on own projects. Additionally, the majority of the identified determinants have a greater impact on the bespoke projects/services.

\subsection{The learning dimension}

During the interviews, in addition to the factors that influenced, positively, the start of the business of the 15 companies involved in this study, others were also mentioned that hindered the entry into the market and influenced the course 
of the business. It also aroused interest in the opinion of respondents about the factors leading startups to failure.

In fact, startups are companies facing a number of challenges. As already indicated, they usually have little or no operational history, have no experience in management, are limited in the resources at their disposal, face multiple influences, and are highly affected by the dynamism of technologies and markets $[5,12]$. According to a study conducted on the development of software in startups [12], it was also found that self-destruction is another factor that leads many startups to failure at the beginning of the activity [13], and that the aggressiveness of the market and the strong competition leads them to operate in chaotic environments $[14,15]$.

According to Ries [3], it is critical for the startups to acquire knowledge resulting from the experience obtained throughout the software development process, even in the first months of the companies. This confirms the idea that it is necessary to have a constant learning of the whole process when a company is started, a factor considered by Ries as essential to foster its sustainability. In fact, this factor proves essential to better orient the business, in order to make known to all stakeholders which are the most/less important aspects that lead the businesses to success.

Therefore, based on the results collected among the 15 companies that are part of this study, an adapted version of the ELDM is proposed. This extended ELDM version takes into account the learning factor, as verified in many of the companies of this study and considered to be a fundamental issue to the business of startups [3].

Although this version retains the format of the initial version of the model, i.e., a four-leaf clover, a flower was added (notably the clover flower) with the indication of the acquired learning that results from the difficulties felt, the mistakes made, the realization of pivots, and the experience acquired throughout the process of developing a company. In this way, a more dynamic dimension is given to the model proposed in [6], by also considering the Lean Startup approach [3].

\subsection{Validity threats}

A series of issues may influence the results of this exploratory study, such as the bias that could be introduced by the researchers who performed the study or the observed data set. In the following, we consider the threats to validity, in a way to discuss the acceptance and accuracy of the findings presented here.

We should not claim that the results are representative of all software startups, or can be generalizable to other economic fields. Though, they provide insights from a set of 15 software startups, located in Portugal. However, even if the total number of companies is relatively low, they equally cover the three considered types of companies.

During the field study, two researchers were responsible for interviewing the participants, collecting and organizing the data, and processing the results. The 


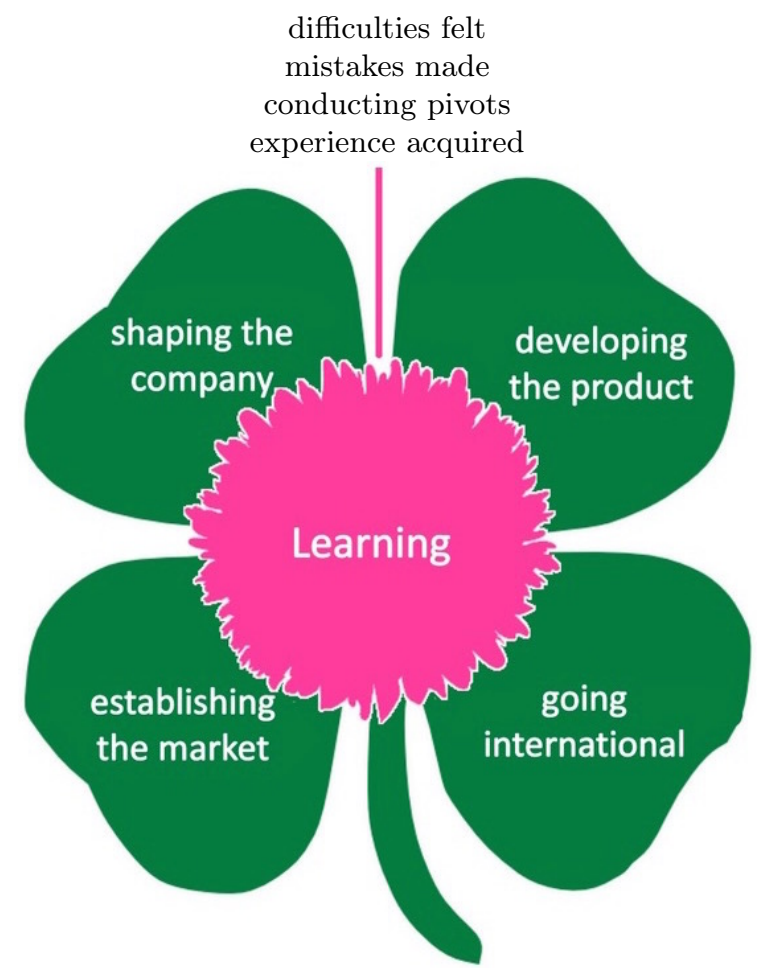

Fig. 3. Extended version of the ELDM with the learning dimension.

two authors conducted the analysis of the gathered data, so there is a risk related to the interpretation of the findings. Nevertheless, we tried to mitigate this validation threat by the use of a software application for the analysis of qualitative data, with follow-up reports that were sent to the interviewees and by discussing the preliminary results at length with all the researchers, supporting the triangulation of the data.

\section{Conclusions}

Several conclusions were obtained, such as the impact of each determinant on the groups of companies identified, as well as the type of internal and external determinants identified in the various aspects of the business. It was also possible to verify that the existence of determinants, which make it difficult for companies to enter the market, influence the course of the business, and that the learning acquired through them and the experience lived during the activity of the company, is essential for business sustainability.

Once analyzed the 15 case studies in this research and reviewed the literature, it can be stated that the experience obtained and the learning acquired 
throughout the process of opening and growing a company, influences the decisions taken by all the actors in the process. These decisions are important to analyze and define which market entry strategies to adopt, taking into account internal and external determinants and the type of company.

In a broader perspective, the various determinants are important in both axes, with a slight tendency towards the companies with own projects. In this way, those who want to open a company to develop their own projects should have more attention to the (internal and external) determinants that can affect the business, such as decisions taken and other factors considered as fundamental.

\section{Acknowledgements}

This work was supported by COMPETE: POCI-01-0145-FEDER-007043 and FCT (Fundação para a Ciência e a Tecnologia) within the Project Scope: UID / CEC / 00319 / 2013.

\section{References}

1. Lowell W. Busenitz. Entrepreneurial risk and strategic decision making: It's a matter of perspective. The Journal of Applied Behavioral Science, 35(3):325-340, 1999. DOI 10.1177/0021886399353005

2. Michael J. Nowak and Charles E. Grantham. The virtual incubator: Managing human capital in the software industry. Research Policy, 29(2):125-134, 2000. DOI 10.1016/S0048-7333(99)00054-2

3. Eric Ries. The lean startup: How today's entrepreneurs use continuous innovation to create radically successful businesses. Crown Publishing Group, 2011.

4. Alexander Osterwalder and Yves Pigneur. Business model generation: A handbook for visionaries, game changers, and challengers. Wiley, 2010.

5. Stanley M. Sutton. The role of process in a software start-up. IEEE Software, 17(4):33-39, July 2000. DOI 10.1109/52.854066

6. Roderick van Cann, Slinger Jansen, and Sjaak Brinkkemper. Software business start-up memories: Key decisions in success stories. Palgrave Macmillan, 2013.

7. Oskari Miettinen, Oleksiy Mazhelis, and Eetu Luoma. Managerial growth challenges in small software firms: A multiple-case study of growth-oriented enterprises. In Pasi Tyrväinen, Slinger Jansen, and Michael A. Cusumano, editors, 1st International Conference of Software Business (ICSOB 2010), volume 51 of Lecture Notes in Business Information Processing, pages 26-37, 2010. DOI 10.1007/978-3642-13633-7_3

8. Detlev J. Hoch, Sandro K. Lindner, Cyriac R. Roeding, and Gert Purkert. Secrets of software success: Management insights from 100 software firms around the world. Harvard Business School Press, 2000.

9. M. Saunders, P. Lewis, and A. Thornhill. Research methods for business students. Prentice Hall, 2009.

10. Instituto Empresarial do Minho. Innovation and entrepreneurship: 15 national success case studies. Technical report, IEMinho, 2011. In Portuguese. 
11. João M. Fernandes and Ricardo J. Machado. Requirements in engineering projects. Lecture Notes in Management and Industrial Engineering. Springer, 2016. DOI 10.1007/978-3-319-18597-2

12. Nicolò Paternoster, Carmine Giardino, Michael Unterkalmsteiner, Tony Gorschek, and Pekka Abrahamsson. Software development in startup companies: A systematic mapping study. Information and Software Technology, 56(10):1200-1218, October 2014. DOI 10.1016/j.infsof.2014.04.014

13. M. Crowne. Why software product startups fail and what to do about it: Evolution of software product development in startup companies. In IEEE International Engineering Management Conference (IEMC 2002), volume 1, pages 338-343, 2002. DOI 10.1109/IEMC.2002.1038454

14. Kathleen M. Eisenhardt and Shona L. Brown. Time pacing: Competing in markets that won't stand still. Harvard Business Review, 76(2):59-69, 1998. URL

15. Alan MacCormack. Product-development practices that work: How internet companies build software. MIT Sloan Management Review, 42(2):75-84, 2001. 